\title{
Numerical Investigation of Temperature Distribution of Thermal Discharge in a River-Type Reservoir
}

\author{
Shuangling Wang ${ }^{1}$, Fajin Chen ${ }^{1 *}$, Wanshun Zhang ${ }^{2}$ \\ ${ }^{1}$ Guangdong Key Laboratory of Coastal Ocean Variability and Disaster Prediction, \\ Guangdong Ocean University, Zhanjiang, China \\ ${ }^{2}$ School of Resource and Environmental Science, Wuhan University, Wuhan, China
}

Received: 12 April 2018

Accepted: 27 October 2018

\begin{abstract}
A 3-D thermal discharge numerical model based on the Navier-Stokes equation, the $k-\varepsilon$ turbulence model, and the temperature diffusion-controlled equation was developed to simulate the 3-D distribution of thermal discharge along a river-type reservoir under different discharge conditions, hydrological conditions and reservoir water levels. Results showed that the thermal discharge from the power plant would have a smaller effect on a deep-water reservoir. Neither $1{ }^{\circ} \mathrm{C}, 2^{\circ} \mathrm{C}$ nor $3^{\circ} \mathrm{C}$ isotherm appear in any scenario conditions. For dam water depths of $155 \mathrm{~m}$ and $175 \mathrm{~m}$, a small envelope area of $0.05^{\circ} \mathrm{C}$ isothermal line was predicted. The isothermal lines of $0.05^{\circ} \mathrm{C}$ and $0.1^{\circ} \mathrm{C}$ covered a small area in all scenario conditions. The temperature increase $500 \mathrm{~m}$ downstream of the discharge point was predicted to be less than $0.05^{\circ} \mathrm{C}$ during dry seasons. The predicted stability time of the temperature increase in each layer was 20 days. It evidences the thermal impact intensity and the extent is different under three scenario conditions. The predicted space-time distribution of the cooling water and the temperature increase provide scientific bases for designing water intake and water management. In the future, the influence of thermal discharge on water quality and aquatic organisms of the reservoir will be discussed based on the simulation results of this study, that is, the variation law of water temperature caused by thermal discharge.
\end{abstract}

Keywords: 3-D model; temperature distribution; thermal discharge; river-type reservoir

\section{Introduction}

Rapid economic and social progress has generally been accompanied by increased electrical power

*e-mail: fjchen04@163.com consumption and, consequently, by a rapidly expanding electricity generating industry. Power plants discharge very large volumes of cooling water that have accumulated much heat in the cooling process, raising the temperature of the water into which it is discharged [1-3]. Waste heat discharge from thermal power plants is one of the main causes of thermal pollution of water [4-9]. This thermal discharge pollution is becoming 
an increasingly serious environmental problem. The analysis of hot-water discharge into different water bodies such as coastal [10-12], bay [13], river [14], lake [15], reservoirs [16-18], and aquifer [19] is important when considering its possible effect on the hydrodynamics, water quality, and the aquatic ecosystem function.

Previous studies have focused on simulating thermal discharge diffusion using physical models [1-3]. With the rapid advancement of computer technology, numerical models have become valuable tools for studying the effects of discharges into the environment. These models vary in levels of complexity and modeling approaches [20-24]. For example, based on numerical models, the effects of topography on the diffusion of thermal discharge in power plants is studied, and the results showed that the influence range of thermal discharge from a coastal power plant is determined by geographic setting [10-11]. Feng et al. performed a two-dimensional mathematical model to study the flow and heat transport under wind in the Douhe reservoir in China, and their results indicated that wind has a significant impact on ecological effects due to thermal discharge from thermal power plant into shallow reservoirs [16]. Azucena et al. provided numerical and experimental investigation to study the physical effects of thermal plumes into the sea, in this research it was indicated that the influence area and the directionality of the thermal plume under a specific extreme weather condition [20]. Bedri et al. established a hydro-environmental model to investigate the effect of cessation of thermal discharge from a power plant on the bathing water quality of Dublin Bay [24].

At present, the 3-D numerical modeling of lakes, coastal and shallow reservoirs are flourishing in thermal discharge research [25-28]. The Delft3D-FLOW model has been used to simulate thermal plume dispersion into the sea caused by a power plant, which solves the shallow-water equations [20]. A 3-D hydrodynamic and temperature numerical simulation has been used to assess the effect on several cooling lakes in the southeastern United States [27]. The program MIKE 3 , which contains a 3-D hydrodynamic module, was used to evaluate the effects of a cooling-water thermal plume in New York Harbor [28]. However, to date, studies on the effects of thermal effluent plume on rivertype reservoirs under different scenario conditions are relatively scarce.

In this study, we present a 3-D numerical model based on the Navier-Stokes (N-S) equation, the $k-\varepsilon$ turbulence model, and the temperature diffusioncontrolled equation to investigate the temperature distribution of thermal discharge in a river-type reservoir under different discharge conditions, different hydrological conditions and different reservoir water levels. The numerical model was validated by carrying out synchronized observations at typical sections. The results indicated that the numerical model is an effective tool for water environmental planning and management research.

\section{Material and Methods}

Basic Governing Equations

Continuity equation:

$$
\frac{1}{h} \frac{\partial h}{\partial t}+\frac{1}{h} \frac{\partial h u}{\partial x}+\frac{\partial w}{\partial z}=0
$$

Momentum equations:

$$
\begin{gathered}
\frac{\partial u}{\partial t}+\frac{1}{h} \frac{\partial u u}{\partial s}+\frac{1}{h} \frac{\partial h v u}{\partial n}+\frac{\partial w u}{\partial z}+\frac{1}{h p} \frac{\partial p}{\partial s}+\frac{g}{h} \frac{\partial \eta}{\partial s}+\frac{v u}{h R}= \\
=\frac{1}{h \rho} \frac{\partial \tau_{s s}}{\partial s}+\frac{1}{h \rho} \frac{\partial h \tau_{s n}}{\partial n}+\frac{1}{\rho} \frac{\partial \tau_{s z}}{\partial z}+\frac{1}{\rho} \frac{\tau_{n z}}{h R} . \\
\frac{\partial v}{\partial t}+\frac{1}{h} \frac{\partial u v}{\partial s}+\frac{1}{h} \frac{\partial h v v}{\partial n}+\frac{\partial w v}{\partial z}+\frac{1}{\rho} \frac{\partial p}{\partial n}+g \frac{\partial \eta}{\partial n}-\frac{u^{2}}{h R}= \\
=\frac{1}{\rho h} \frac{\partial \tau_{s n}}{\partial s}+\frac{1}{h \rho} \frac{\partial h \tau_{n n}}{\partial n}+\frac{1}{\rho} \frac{\partial \tau_{n z}}{\partial z}-\frac{1}{\rho} \frac{\tau_{s s}}{h R} . \\
\frac{\partial w}{\partial t}+\frac{1}{h} \frac{\partial u w}{\partial s}+\frac{1}{h} \frac{\partial h w}{\partial n}+\frac{\partial w w}{\partial z}+\frac{1}{\rho} \frac{\partial p}{\partial z}= \\
=\frac{1}{\rho h} \frac{\partial \tau_{s z}}{\partial s}+\frac{1}{h \rho} \frac{\partial h \tau_{n r}}{\partial n}+\frac{1}{\rho} \frac{\partial \tau_{z z}}{\partial z} .
\end{gathered}
$$

$k$ equation:

$$
\begin{aligned}
& \frac{\partial k}{\partial t}+\frac{1}{h} \frac{\partial u k}{\partial s}+\frac{1}{h} \frac{\partial h v k}{\partial n}+\frac{\partial w k}{\partial z}=\frac{1}{h} \frac{\partial}{\partial s}\left(\frac{v_{t}}{\sigma k} \frac{1}{h} \frac{\partial k}{\partial s}\right)+ \\
& +\frac{1}{h} \frac{\partial}{\partial n}\left(\frac{v_{t} h}{\sigma_{\varepsilon}} \frac{\partial k}{\partial n}\right)+\frac{\partial}{\partial z}\left(\frac{v_{t}}{\sigma k} \frac{\partial k}{\partial s}\right)+G-\varepsilon+D .
\end{aligned}
$$

$\varepsilon$ equation:

$$
\begin{gathered}
\frac{\partial \varepsilon}{\partial t}+\frac{1}{h} \frac{\partial u \varepsilon}{\partial s}+\frac{1}{h} \frac{\partial h v \varepsilon}{\partial n}+\frac{\partial w \varepsilon}{\partial z}=\frac{1}{h} \frac{\partial}{\partial s}\left(\frac{v_{t}}{\sigma_{\varepsilon}} \frac{1}{h} \frac{\partial \varepsilon}{\partial s}\right)+\frac{1}{h} \frac{\partial}{\partial n}\left(\frac{v_{t} h}{\sigma_{\varepsilon}} \frac{\partial \varepsilon}{\partial n}\right)+ \\
+\frac{\partial}{\partial z}\left(\frac{v_{t}}{\sigma_{\varepsilon}} \frac{\partial \varepsilon}{\partial z}\right)+C_{\varepsilon 1} f_{1} \frac{\varepsilon}{k} G-C_{\varepsilon 2} f_{2} \frac{\varepsilon^{2}}{k}+E,
\end{gathered}
$$

...where $v_{t}$ is the turbulent eddy viscosity defined by $v_{t}=c_{m} f_{m}^{t} k^{2 / e}$; and $f_{1}, f_{2}, f_{\mu}$ are the turbulent model constants. $D=0, E=0, f_{1}=1, f_{2}=1$ and $f_{\mu}=1$ for the standard $k-\varepsilon$. For the low-Reynolds number $k-\varepsilon$ model, $f_{1}, f_{2}$ and $f_{\mu}$ are specified as:

$$
\begin{aligned}
& f_{1}=1, f_{2}=1-0.22 e^{\left.\tau^{2}, R_{T} / f_{\mu}^{6}\right)}=1-e^{-0.0115 \tilde{Y}_{+}} \\
& R_{T}=\frac{k^{2}}{v \varepsilon}, E=-2 v\left(\varepsilon / y^{2}\right) e^{-0.5 \tilde{y}+} \\
& D=-2 v k / y^{2}, y^{+}=y k^{1 / 2} / v
\end{aligned}
$$


$G$ is the turbulence generation term with the following forms:

$$
\begin{gathered}
G=v_{t}\left\{2\left[\left(\frac{1}{h} \frac{\partial w}{\partial s}+\frac{v}{h R}\right)^{2}+\left(\frac{\partial v}{\partial n}\right)^{2}+\left(\frac{\partial w}{\partial z}\right)^{2}\right]+\left(\frac{1}{h} \frac{\partial w}{\partial s}+\frac{\partial u}{\partial z}\right)^{2}+\right. \\
\left.+\left(\frac{1}{h} \frac{\partial w}{\partial s}+\frac{\partial u}{\partial n}-\frac{u}{n R}\right)^{2}+\left(\frac{\partial w}{\partial n}+\frac{\partial v}{\partial z}\right)^{2}\right\} .
\end{gathered}
$$

Turbulent stresses $\tau_{i j}$ are calculated by the $k-\varepsilon$ turbulence model, which employs the following eddy viscosity relationship:

$$
\begin{aligned}
& \frac{\tau_{s s}}{\rho}=2 v_{e}\left(\frac{1}{h} \frac{\partial u}{\partial s}+\frac{v}{h R}\right), \frac{\tau_{n s}}{\rho}=v_{e}\left(\frac{1}{h} \frac{\partial v}{\partial s}+\frac{\partial u}{\partial n}-\frac{v}{h R}\right), \\
& \frac{\tau_{z s}}{\rho}=v_{e}\left(\frac{1}{h} \frac{\partial w}{\partial s}+\frac{\partial u}{\partial z}\right), \frac{\tau_{n n}}{\rho}=2 v_{e}\left(\frac{\partial v}{\partial n}\right), \\
& \frac{\tau_{\text {zn }}}{\rho}=v_{e}\left(\frac{\partial w}{\partial n}+\frac{\partial v}{\partial z}\right), \frac{\tau_{\text {zz }}}{\rho}=2 v_{e}\left(\frac{\partial w}{\partial z}\right),
\end{aligned}
$$

..where $v_{e}=v+v_{t}$. The other constants for the $k-\varepsilon$ turbulence model are:

$C_{\mu}=0.09, C_{\varepsilon 1}=1.44, C_{\varepsilon 2}=1.92, \sigma_{k}=1.0, \sigma_{\varepsilon 2}=1.92$.

Temperature diffusion-controlled equation:

$$
\begin{aligned}
\frac{\partial \Delta T}{\partial t}+ & u \frac{\partial \Delta T}{\partial x}+v \frac{\partial \Delta T}{\partial y}+w \frac{\partial \Delta T}{\partial z}=\frac{\partial}{\partial x}\left(D_{x} \frac{\partial \Delta T}{\partial x}\right)+ \\
& +\frac{\partial}{\partial y}\left(D_{y} \frac{\partial \Delta T}{\partial y}\right)+\frac{\partial}{\partial z}\left(D_{z} \frac{\partial \Delta T}{\partial z}\right),
\end{aligned}
$$

...where $\Delta T$ is the excess water temperature; $\Delta T=T-T_{\infty}$ ( $T$ is the water temperature; $T_{\infty}$ is the temperature of the natural water); and $D_{x}, D_{y}$ and $D_{z}$ are the $x$-, $y$ - and $z$-directions of the diffusion coefficient $\left(\mathrm{m}^{2} / \mathrm{s}\right)$, which are obtained by the empirical model or the $k-\varepsilon$ double-turbulence model.

Channel roughness was mainly calculated from the measured flow data. The turbulent viscosity coefficient was determined from an empirical formula adopting different diffusion coefficients for each layer. The main parameters of the temperature field are the thermal diffusion coefficient and the heat transfer coefficient.

The evaporation and heat loss coefficient of the water surface, $k$, is given by:

$$
\begin{gathered}
k_{s}=\left(\frac{d e_{s}}{d T}+b\right) \alpha+4 \varepsilon \sigma\left(T_{s}+273\right)^{3}, \\
\alpha=\left[22.0+12.5 W_{1.5}^{2}+2.0 \times\left(T_{s}-T_{\alpha}\right)\right]^{1 / 2},
\end{gathered}
$$

...where $b=6.264\left(\mathrm{hPa} /{ }^{\circ} \mathrm{C}\right) ; \sigma=5.67 \times 10^{-8}\left(\mathrm{~W} / \mathrm{m}^{2} . \mathrm{k}^{4}\right)$; and $W_{1.5}(\mathrm{~m} / \mathrm{s})$ is the wind velocity $1.5 \mathrm{~m}$ above the water surface. (Wind velocity was assumed to be $0 \mathrm{~m} / \mathrm{s}$.) $T_{s}$ is the water surface temperature; $T_{a}$ is the air temperature; and $\varepsilon$ is the emissivity of the water surface, equal to 0.97 .

The Chinese code for designing industrial circulating cooling water (GBT50102-2003) states that $k_{s}$ is to be estimated from annual average temperature, water temperature, wind speed, relative humidity and air pressure of representative stations along the simulated river. On this basis, the values lie within the ranges $10.5-18.0 \mathrm{~W} /\left(\mathrm{m}^{2} . \mathrm{K}\right)$ in winter and $19.5-44.0 \mathrm{~W} /\left(\mathrm{m}^{2} . \mathrm{K}\right)$ in summer.

\section{Definite Conditions}

(1) Surface of reservoir $(z=0)$

$$
\begin{gathered}
\left.A_{v} \frac{\partial u}{\partial z}\right|_{s}=0, \\
\left.A_{v} \frac{\partial v}{\partial z}\right|_{s}=0, \\
D_{z} \frac{\partial \Delta T}{\partial z}=\frac{K_{s} \Delta T}{\rho C_{p}} .
\end{gathered}
$$

(2) Bottom of reservoir $(z=h)$

$$
\begin{gathered}
\left.A_{v} \frac{\partial u}{\partial z}\right|_{b}=\tau_{b x}=\rho \lambda u \sqrt{u^{2}+v^{2}}, \\
\left.A_{v} \frac{\partial v}{\partial z}\right|_{b}=\tau_{b y}=\rho \lambda v \sqrt{u^{2}+v^{2}}, \\
\frac{\partial R_{i}}{\partial z}=S_{m},
\end{gathered}
$$

...where $\tau_{b x}$ and $\tau_{b v}$ are the friction stress values in the $x$ - and $y$-directions at the bottom of the reservoir $\left(\mathrm{N} / \mathrm{m}^{2}\right)$; $\rho$ is the density of water $\left(\mathrm{kg} / \mathrm{m}^{3}\right)$; and $\lambda$ is the coefficient of friction stress.

(3) Closed boundary

$$
(u, v)_{n}=0, T_{n}=0, R_{i n}=0 \text {. }
$$

(4) Open boundary

$$
(u, v)_{n}=\left(u_{b}(t), v_{b}(t)\right), T_{n}=T_{b}(t), R_{i n}=R_{i b}(t) .
$$

\section{Initial and Boundary Conditions}

(1) Initial conditions

$$
\begin{aligned}
& u(x, y, t)_{t=0}=u_{0}(x, y), \\
& v(x, y, t)_{t=0}=v_{0}(x, y), \\
& \zeta(x, y, t)_{t=0}=\zeta_{0}(x, y) .
\end{aligned}
$$




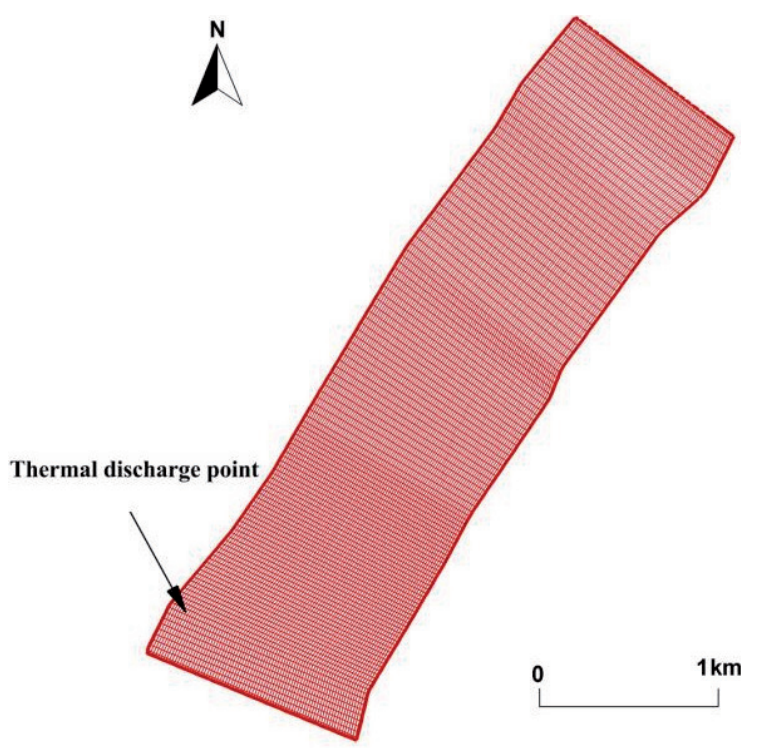

Fig. 1. Arrangement of 3-D mesh.

(2) Boundary conditions

The calculation region has two types of boundary: solid and water. The given slip condition at the solid boundary is:

$$
\overrightarrow{v \cdot n}=0,
$$

...where $\bar{v}$ is the velocity vector and $\bar{n}$ is the boundary normal unit vector. Water flow (upstream boundary) and water level (downstream boundary) are included in the water boundary.

\section{Numerical Solutions}

Equations are discriminated within a finite volume by adopting the upwind scheme to compute the convection term on non-orthogonal, quadrilateral grids. The correction equation and the velocity correction equation of the free-surface are obtained by using the improved SIMPLE algorithm developed by $\mathrm{Lu}$ et al. [29]. Equations for velocity, pressure and free surface, which are part of the algebraic equations in diagonal form, are rapidly solved by the SIMPLE process [30].

\section{Study Area and Calculation Conditions}

The power plant site is located in a river-type reservoir with perennial backwater, and where the water is deep. A 3-D model was applied after considering vertical change in water level in the calculation region. Based on the flow pattern characteristic of the study area, a 3-D thermal discharge model was developed to simulate the migration and diffusion of the thermal discharge and the temperature field from $0.5 \mathrm{~km}$ upstream of the outlet to $4 \mathrm{~km}$ downstream.

After considering all the factors relating to the power plant, including the river regime and the possible effects of the power plant on the engineering and hydrological properties of the river, the reach was calculated by generating a mesh based on a topographic map developed for this purpose. The minimum size of the grid ranges from 20 to $40 \mathrm{~m}$, with a vertical grid spacing of $5 \mathrm{~m}$. The grid refinement was properly done near the thermal discharge point.

The outlet for the hot cooling water from the power station is to be located on the left-hand side of the river channel, looking downstream. The elevation is $137 \mathrm{~m}$; the discharge flow is approximately $2 \mathrm{~m}^{3} / \mathrm{s}$ in summer and $1.5 \mathrm{~m}^{3} / \mathrm{s}$ in winter.

Three scenario conditions were employed:

1) Most favorable working conditions: summer discharge flow, average flow of the reach at the site from June to September in typical years $(p=10 \%)$, and water level in front of the dam at $145 \mathrm{~m}$.

2) Normal working conditions: summer discharge flow, average flow of the reach at the site in May in typical years $(\mathrm{p}=50 \%)$, and water level in front of the dam at $155 \mathrm{~m}$.

3) Least favorable working conditions: winter discharge flow, minimum flow of the reach at the site in typical years $(\mathrm{p}=90 \%)$, and water level in front of the dam at $175 \mathrm{~m}$.

These are summarized in Table 1.

\section{Model Validation}

Water level and flow velocity were validated using field data collected at a test section on November 15, 2016, and on May 15 and July 15, 2017. The section was $0.5 \mathrm{~km}$ from the upstream inlet and near the power plant. Table 2 and Fig. 2 show the validation results. The calibration conditions and water level validation results are shown in Table 2. The 3-D stratified flow velocity validation results at $0.0,0.2,0.4,0.6,0.8$ and $1.0 \times$ water depth are shown in Fig. 2 .

The calculated results for the test section may be summarized as follows: the maximum relative error of the calculated water level was within $0.83 \mathrm{~m}$; the

Table 1. Scenario condition.

\begin{tabular}{|c|c|c|c|c|}
\hline Scenario & Discharge flow $\left(\mathrm{m}^{3} / \mathrm{s}\right)$ & Flow condition & Upstream inflow $\left(\mathrm{m}^{3} / \mathrm{s}\right)$ & Water level in front of dam $(\mathrm{m})$ \\
\hline 1 & Flow in summer $=2.0$ & Average flow June-Sept $(\mathrm{p}=10 \%)$ & 29200 & 145 \\
\hline 2 & Flow in summer $=2.0$ & Average flow in May $(\mathrm{p}=50 \%)$ & 10500 & 155 \\
\hline 3 & Flow in winter $=1.5$ & Minimum flow $(\mathrm{p}=90 \%)$ & 2900 & 175 \\
\hline
\end{tabular}


Table 2. Model calibration conditions and results of water level validation.

\begin{tabular}{|c|c|c|c|}
\hline Date & 2016.11 .15 & 2017.5 .15 & 2017.7 .15 \\
\hline Flow $\left(\mathrm{m}^{3} / \mathrm{s}\right)$ & 4800 & 9400 & 22600 \\
\hline $\begin{array}{c}\text { Measured water level } \\
(\mathrm{m})\end{array}$ & 164.28 & 152.37 & 145.35 \\
\hline $\begin{array}{c}\text { Simulated water level } \\
(\mathrm{m})\end{array}$ & 163.45 & 152.02 & 145.22 \\
\hline Error (m) & -0.83 & -0.35 & -0.13 \\
\hline
\end{tabular}

maximum relative error of the calculated average velocity was within $8.37 \%$, the maximum relative error of the calculated stratified flow was within $10 \%$. The calculated values are consistent with the measured data. Hence, the calibrated parameters were considered to be valid for simulation and prediction.
Table 3. Depth of water in different layers of the reservoir.

\begin{tabular}{|c|c|c|c|}
\hline \multirow{2}{*}{ Water level layer } & \multicolumn{3}{|c|}{ Water level in front of the dam (m) } \\
\cline { 2 - 4 } & 145 & 155 & 175 \\
\hline Surface layer & 140 to 145 & 148 to 155 & 164 to 175 \\
\hline Middle layer & 130 to 140 & 134 to 148 & 142 to 164 \\
\hline Bottom layer & $<130$ & $<134$ & $<142$ \\
\hline
\end{tabular}

\section{Results and Discussion}

The depth of the water was divided into several layers according to the section of the plant in the river and the different water levels in front of the dam. The maximum length, maximum width, and envelope area of the isotherms over the range of temperatures were calculated for the surface layer, middle layer and bottom layer of the river. Table 3 gives the depth of water in
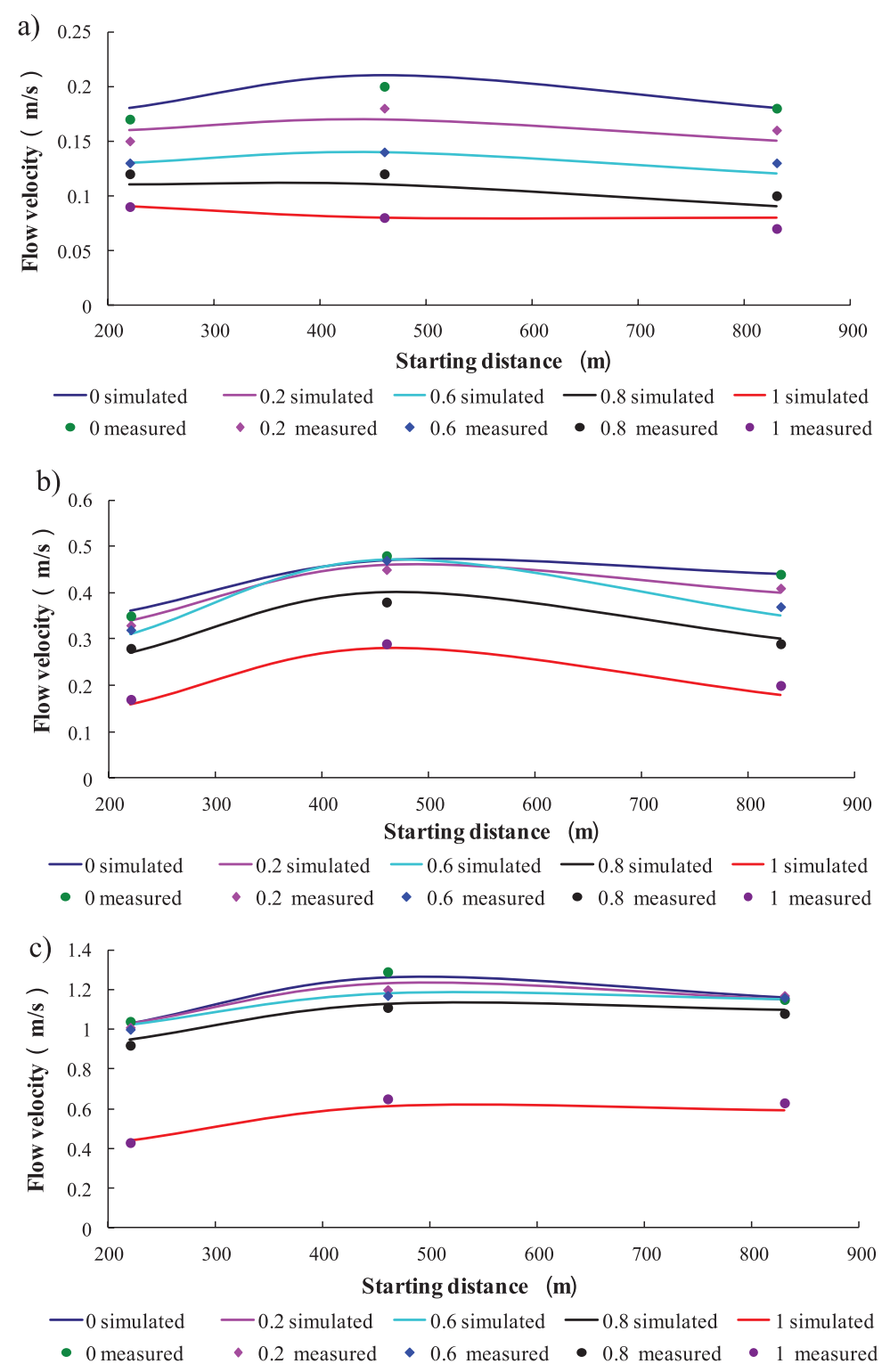

Fig. 2. Stratified flow verification results: a) 2016.11.15, b) 2017.05.15, c) 2017.07.17 
these three layers of the reservoir; Fig. 3 shows the results of each calculation Scenario.

Fig. 3 shows that the hot cooling water from the power plant (the thermal discharge) was predicted to have a minimal effect on the water temperature of the river near the plant. The thermal discharge rapidly mixed with river water from upstream because the amount of water in the upper reaches was greater when the water levels in front of the dam reservoir were 145 and $155 \mathrm{~m}$, such that the hot water was discharged into the middle layer of the river. When the water level in front of the dam reservoir was $175 \mathrm{~m}$, the thermal water was discharged into the bottom layer of the river. The thermal discharge was minimal relative to the amount of water in the reservoir, despite the relatively small flow of the river upstream. Therefore, no isotherms of $3^{\circ} \mathrm{C}, 2^{\circ} \mathrm{C}$ or $1^{\circ} \mathrm{C}$ appeared in any of the calculation scenario results. However, a small zone of $0.5^{\circ} \mathrm{C}$ isotherms appeared in the results of scenarios 2 and 3 ("normal" and "least favorable" working conditions). The isothermal envelope areas for $0.1^{\circ} \mathrm{C}$ and $0.05^{\circ} \mathrm{C}$ were small for each scenario. a)

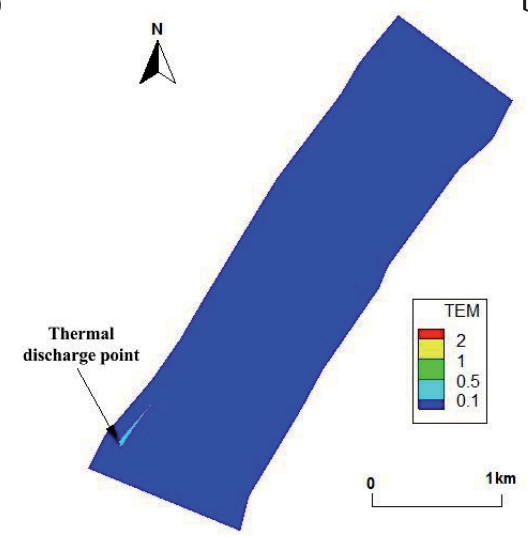

d)

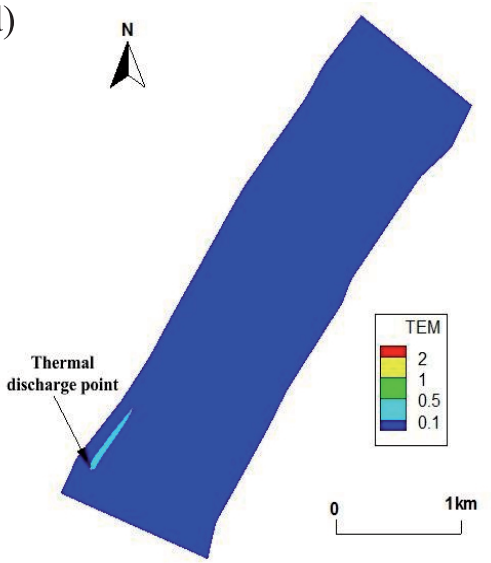

g)

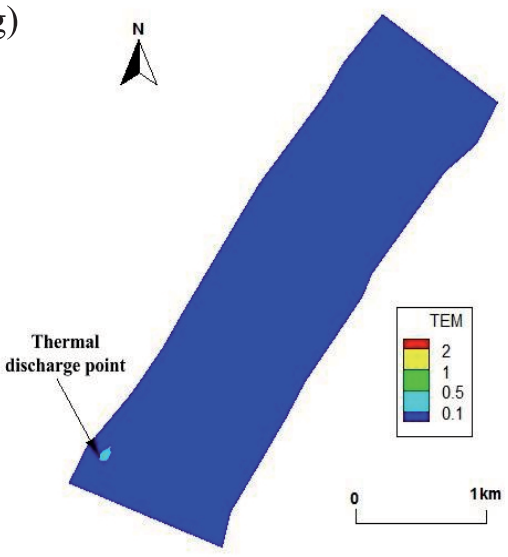

b)

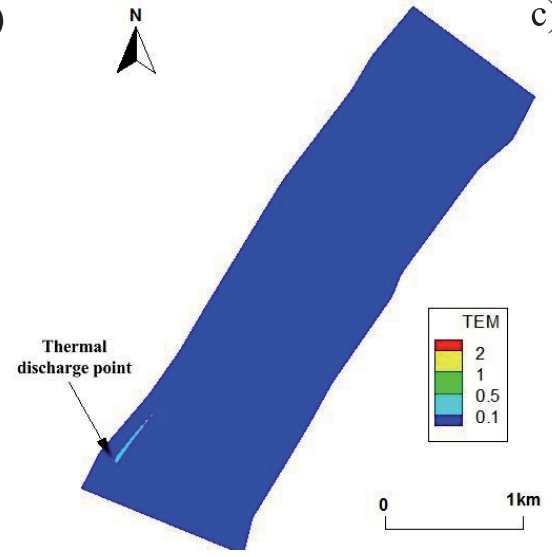

e)

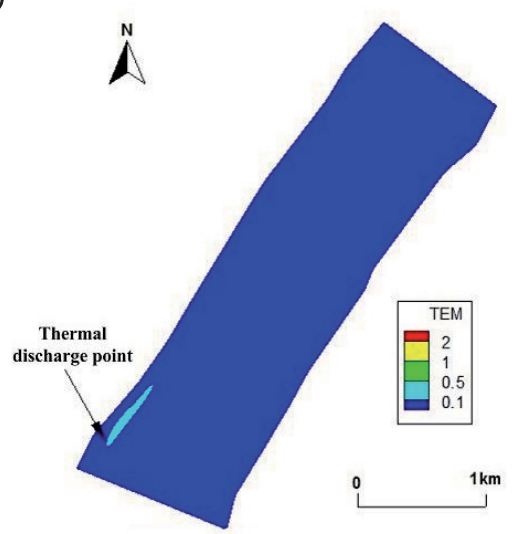

h)



c)

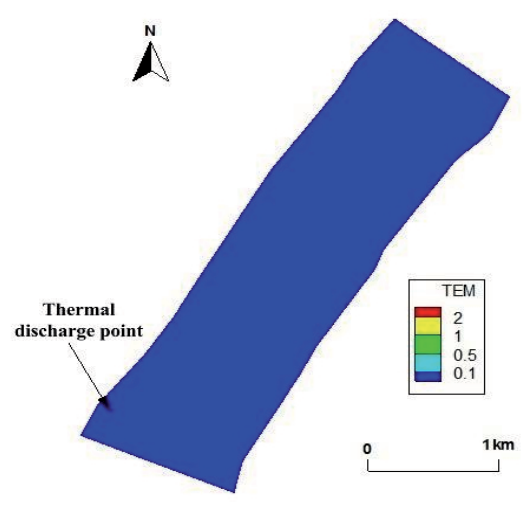

f)

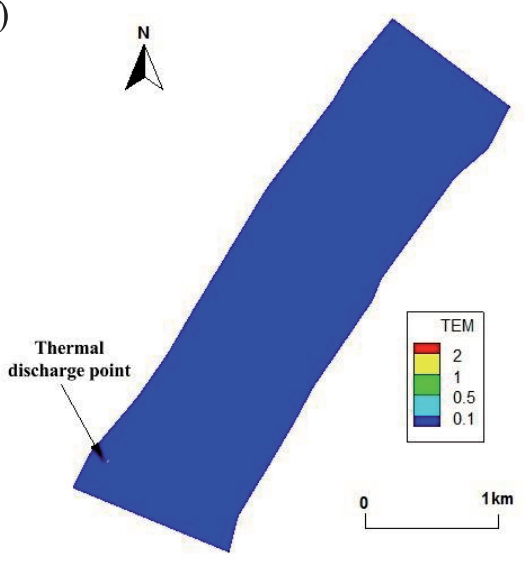

i)

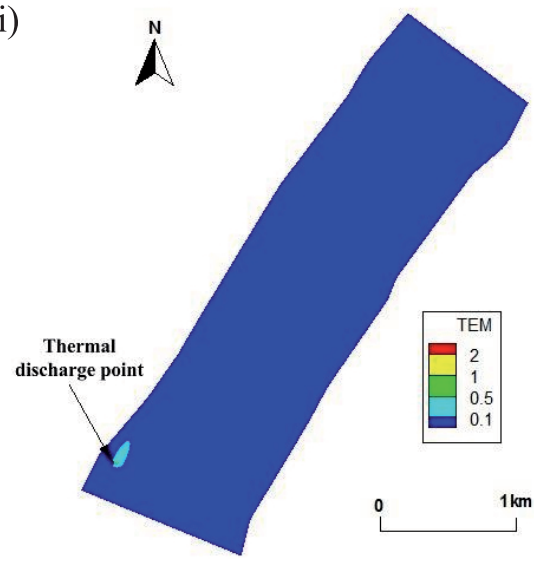

Fig. 3. Temperature increase distribution for different conditions: a)Surface layer of Scenario 1, b) Middle layer of Scenario 1, c) Bottom layer of Scenario 1, d)Surface layer of Scenario 2, e) Middle layer of Scenario 2, f) Bottom layer of Scenario 2, g) Surface layer of Scenario 3, h) Middle layer of Scenario 3, i) Bottom layer of Scenario 3. 
Table 4. Maximum temperature increase and stable time downstream of discharge point.

\begin{tabular}{|c|c|c|c|c|c|c|c|}
\hline \multirow{2}{*}{ No } & \multirow{2}{*}{$\begin{array}{c}\text { Distance } \\
\text { from outlet } \\
(\mathrm{m})\end{array}$} & $\begin{array}{c}\text { Maximum } \\
\text { temperature } \\
\text { increase }\left({ }^{\circ} \mathrm{C}\right)\end{array}$ & $\begin{array}{c}\text { Stable time } \\
(\mathrm{d})\end{array}$ & $\begin{array}{c}\text { Maximum } \\
\text { temperature } \\
\text { increase }\left({ }^{\circ} \mathrm{C}\right)\end{array}$ & $\begin{array}{c}\text { Stable time } \\
(\mathrm{d})\end{array}$ & $\begin{array}{c}\text { Maximum } \\
\text { temperature } \\
\text { increase }\left({ }^{\circ} \mathrm{C}\right)\end{array}$ & $\begin{array}{c}\text { Stable time } \\
(\mathrm{d})\end{array}$ \\
\hline 1 & 0 & 0.42 & 8 & 0.58 & 8 & 0.63 & 8 \\
\hline 2 & 500 & - & 20 & - & 20 & - & 20 \\
\hline 3 & 1000 & - & - & - & - & - & - \\
\hline 4 & 2000 & - & - & - & - & & - \\
\hline 5 & 3000 & - & - & - & - & - \\
\hline
\end{tabular}

No $0.5^{\circ} \mathrm{C}$ isotherms appeared in the surface layer for any of the scenario conditions, although it was evident in the middle layer for scenarios 2 and 3, with a maximum length of $48 \mathrm{~m}$, a maximum width of $27 \mathrm{~m}$, and a maximum area of $0.0011 \mathrm{~km}^{2}$. The $0.5^{\circ} \mathrm{C}$ isotherm also appeared in the bottom layer for scenario 3 , with a maximum length of $55 \mathrm{~m}$, a maximum width of $27 \mathrm{~m}$, and a maximum area of $0.0012 \mathrm{~km}^{2}$. An isotherm of $0.1^{\circ} \mathrm{C}$ appeared in all scenario conditions, with a maximum length of $559 \mathrm{~m}$, a maximum width of $101 \mathrm{~m}$, and a maximum area of $0.032 \mathrm{~km}^{2}$. Results show that the vertical distribution of water temperature is different under three scenario conditions, which confirms the results of previous studies. Kirillin et al.


Fig. 4. Temperature increases at five locations downstream of the discharge point: a) Surface layer, b) Middle layer, c) Bottom layer. 
reported that the consequences of thermal pollution are qualitatively different from the simple surface warming and stronger temperature stratification in the summer, as initially expected [15]. Marti-Cardona et al. observed that the temperature rise became smaller as the spread of thermal discharge moved toward the downstream of the river [17]. Also, Parshakova et al. reported that the vertical temperature distribution in the wastewater reservoirs is inhomogeneous [18].

The shape of the temperature-increase envelope curve differed significantly between flood seasons and dry seasons. A long, narrow envelope curve was seen in flood seasons when the greater volume of water in the upper reaches of the river raised the water level and lowered the current velocity in the reservoir, in dry seasons the envelope curve was shorter and wider. Our results were consistent with Kirillin et al., who pointed out that industrial thermal pollution in temperate lakes during winter is stored in the deep water column until the next winter, whereas heat added in the summer dissipates relatively rapidly into the atmosphere [15]. Kirillin et al. also reported that a remarkable effect of thermal pollution consisted of strong vertical mixing in winter produced by the discharge of warm water into the lake when ambient water temperatures were below $4^{\circ} \mathrm{C}[15]$.

Temperature increase curves under least favorable conditions (i.e., calculation scenario 3) were plotted for five selected locations in order to illustrate the maximum temperature increases and stability times (Table 4; Fig. 4).

For least favorable conditions, the simulated maximum temperature increase in the river downstream of the hot cooling water outlet was $0.63^{\circ} \mathrm{C}$. The simulated maximum increase in surface water temperature was $0.42^{\circ} \mathrm{C}$. The simulated temperature increase $500 \mathrm{~m}$ downstream of the outlet was less than $0.05^{\circ} \mathrm{C}$. The hot water outlet in the model was located at the bottom of the river on the left-hand bank, looking downstream. The simulated temperature increase at the centerline and at the bank of the river opposite the outlet was less than $0.05^{\circ} \mathrm{C}$. It was predicted that the thermal discharge would not affect the temperature of the river water beyond the river centerline. The heated water was predicted to rise to the surface and be transported past the left-hand bank of the river by the river flow, and would not influence the temperature of the river water $1000 \mathrm{~m}$ downstream of the discharge point. MartiCardona et al. also observed that the reservoir impact on the river longitudinal temperature gradient at different times of the year [17].

By changing the density gradient of the water body, the thermal discharge produces secondary dynamic action for the local three-dimensional water body and forms vertical stratified flow. Because the hot water outlet was located at the bottom of the river, the maximum temperature increase from the bottom to the surface was $0.63,0.58$ and $0.42^{\circ} \mathrm{C}$, respectively (Table 4). The thermal discharge at the discharge outlet was mixed rapidly with the reservoir water body, and the temperature predicted to stabilize each layer was relatively short, which was 8 days. At $500 \mathrm{~m}$ of the discharge outlet, the temperature change of the water body caused by the thermal discharge was small, and the exchange intensity of the water body was weakened. Therefore, the temperature was predicted to stabilize here for a longer period of time, that is, 20 days.

\section{Conclusions}

A 3-D thermal discharge numerical model was developed based on the Navier-Stokes equations, the $k-\varepsilon$ turbulence model and the temperature diffusioncontrolled equation. The model was applied to the case of a power plant in a deep-water reservoir by simulating and predicting the migration and diffusion of thermal discharge. Results show that the space-time distribution of the cooling water and the temperature increase is different under three scenario conditions. It also evidences that suitably calibrated parameters can be used to simulate and predict thermal discharge in a deep-water reservoir. The thermal discharge along the river-type reservoir will affect the growth, survival and reproduction of aquatic species, and affect the water quality of the reservoir. The simulation results of this study can improve the water quality prediction level and ensure the water environment safety in the basin, therefore the numerical model can be employed as a tool for effective water management.

\section{Acknowledgements}

The authors are grateful for financial support from the Guangdong Natural Science Foundation of China (2016A030312004), the International Science and Technology Cooperation Project (GASI-IPOVAI-04), and the Project of Enhancing School with Innovation of Guangdong Ocean University (GDOU2014050201, GDOU2013010203, GDOU2013050201).

\section{References}

1. VIGANDER S., ELDER R.A., BROOKS N.H. Internal hydraulics of thermal discharge diffusers. Journal of the Hydraulics Division, 96, 509, 1970.

2. KOKAJI I. The present status for thermal discharge of nuclear power plant. Progress in Nuclear Energy, 29, 413, 1995.

3. LANGFORD T.E.L. Thermal discharges and pollution. Encyclopedia of Ocean Sciences 359 (9317), 10, 2001.

4. ZHAO Y.J., ZENG L., ZHANG A.L., WU Y.H. Response of current, temperature, and algae growth to thermal discharge in tidal environment. Ecological Modelling, 318, 283, 2015.

5. ARIELI R.N., ALMOGI-LABIN A., ABRAMOVICH S., HERUTET B. The effect of thermal pollution on benthic foraminiferal assemblages in the Mediterranean shoreface 
adjacent to Hadera power plant (Israel). Marine Pollution Bulletin, 62 (5), 1002, 2011.

6. CARDOSO-MOHEDANO J.G., BERNARDELLO R., SANCHEZ-CABEZA J.A., RUIZ-FERNÁNDEZ A.C., ALONSO-RODRIGUEZ R., CRUZADO A. Thermal impact from a thermoelectric power plant on a tropical coastal lagoon. Water Air \& Soil Pollution, 226 (1), 1, 2015.

7. BORK I., MAIER-REIMER E. On the spreading of power plant cooling water in a tidal river applied to the river Elbe. Advances in Water Resources, 1 (3), 161, 1978.

8. RAPTIS C.E., BOUCHER J.M., PFISTER S. Assessing the environmental impacts of freshwater thermal pollution from global power generation in LCA. Science of the Total Environment, 580, 1014, 2016.

9. RAPTIS C.E., PFISTER S. Global freshwater thermal emissions from steam-electric power plants with oncethrough cooling systems. Energy, 97, 46, 2016.

10. CHENG Y.L., JING Q.Z.H. Effects of topography on diffusion of thermal discharge in power plant. Procedia Environmental Sciences, 11 (11), 618, 2011.

11. JIA H.L., ZHENG S., XIE J., YING X.M., ZHANG C.P. Influence of geographic setting on thermal discharge from coastal power plants. Marine Pollution Bulletin, 111 (1-2), 106, 2016.

12. TITELBOIM D., ALMOGI-LABIN A., HERUT B., KUCERA M., SCHMIDT C., HYAMS-KAPHZAN O., OVADIA O., ABRAMOVICH S. Selective responses of benthic foraminifera to thermal pollution. Marine Pollution Bulletin, 105 (1), 324, 2016.

13. LI X.Y., Li B., SUN X.L. Effects of a coastal power plant thermal discharge on phytoplankton community structure in Zhanjiang Bay, China. Marine Pollution Bulletin, 81 (1), 210, 2014.

14. LOGAN L.H., STILLWELL A.S. Probabilistic assessment of aquatic species risk from thermoelectric power plant effluent: Incorporating biology into the energy-water nexus. Applied Energy, 210, 434, 2018.

15. KIRILLIN G., SHATWELL T., KASPRZAK P. Consequences of thermal pollution from a nuclear plant on lake temperature and mixing regime. Journal of Hydrology, 496 (496), 47, 2013.

16. FENG L., CHEN B., HAYAT T., ALSAEDI A., AHMAD B. Modelling the influence of thermal discharge under wind on algae. Physics and Chemistry of the Earth, s 7982, 108, 2015.

17. MARTI-CARDONA B., BOFILL M.A., RODRIGUEZ J.P., PIPIA L. Thermal remote sensing for reservoir modelling and management. ESA Living Planet Symposyum. 2016.

18. PARSHAKOVA Y.N., LYUBIMOVA T.P. Computer modelling of technogenic thermal pollution zones in large water bodies. Computer Simulations in Physics and beyond, 955, 01, 2017.

19. GANGULY S., KUMAR M.S.M., DATE A., AKBARZADEH A. Numerical investigation of temperature distribution and thermal performance while charging-discharging thermal energy in aquifer. Applied Thermal Engineering, 115, 756, 2017.

20. AZUCENA D.C., HECTOR B.P., HERMILO R.L. Numerical modeling of water thermal plumes emitted by thermal power plants. Water, 8 (11), 482, 2016.

21. NIKULENKOV A.M., DVORNIKOV A.Y., RUMYNIN V.G., RYABCHENKO V.A., VERESCHAGINA E.A. Assessment of allowable thermal load for a river reservoir subject to multi-source thermal discharge from operating and designed beloyarsk NPP Units (South Ural, Russian Federation). Environmental Modeling and Assessment, 3, 1, 2017.

22. POORNIMA E.H., RAJADURAI M., RAO T.S., ANUPKUMAR B., RAJAMOHAN R., NARASIMHAN S.V., RAO V.N.R., VENUGOPALAN V.P. Impact of thermal discharge from a tropical coastal power plant on phytoplankton. Journal of Thermal Biology, 30 (4), 307, 2005.

23. CHUANG Y.L., YANG H.H., LIN H.J. Effects of a thermal discharge from a nuclear power plant on phytoplankton and periphyton in subtropical coastal waters. Journal of Guangxi Vocational \& Technical College, 61 (4), 197, 2012.

24. BEDRI Z., BRUEN M., DOWLEY A., MASTERSON B. Environmental consequences of a power plant shut-down: a three-dimensional water quality model of Dublin Bay. Marine Pollution Bulletin, 71 (1-2), 117, 2013.

25. KOLLURU V.S., BUCHAK E.M., BRINKMANN P.E. Hydrodynamic modeling of coastal LNG cooling water discharge. Journal of Energy Engineering, 129 (1),16, 2012.

26. GANGULY S., KUMAR M.M. Geothermal reservoirs-A brief review. Journal of the Geological Society of India, 79 (6), 589, 2012.

27. WU J., BUCHAK E.M., EDINGER J.E., KOLLURU V.S. Simulation of cooling-water discharges from power plants. Journal of Environmental Management, 61 (1), 77, 2001.

28. LOWE S.A., SCHUEPFER F., DUNNING D.J. Case Study: Three-dimensional hydrodynamic model of a power plant thermal discharge. Journal of Hydraulic Engineering, 135 (4), 247, 2009.

29. LU W.Z., ZHANG W.S., CUI C.Z.A., LEUNG A.Y.T. numerical analysis of free-surface flow in curved open channel with velocity-pressure-free-surface correction. Computational Mechanics, 33, 215, 2004.

30. ZHANG W.S., ZHAO Y.X., XU Y.H., WANG Y.G., PENG H., XU G.H. 2-D numerical simulation of radionuclide transport in the lower Yangtze River. Journal of Hydrodynamics, 24, 702, 2012. 